\title{
Supporting Online Material for \\ Late Pleistocene and Holocene Uplift History of Cyprus: I mplications for Active Tectonics along the Southern Margin of the Anatolian Microplate
}

by

Richard Harrison, Efthymios Tsiolakis, Byron Stone, Alan Lord, John McGeehin, Shannon Mahan, and Pete Chirico [Paper \#Anat-115]

\section{Brief Luminescence Explanation}

\section{Luminescence Data and Graphics}

Some minerals (quartz, feldspar) store energy from both the sun and radioactive decay of trace elements (mainly $\mathrm{U}$, Th, K, and Rb). Over time, the amount of energy builds up in traps within the imperfect crystal lattices of the minerals. Exposure to heat, light, or high pressure can release the energy from trapping sites and permit recombination, which "resets" the system. Luminescence ages, which represent the amount of time elapsed since the mineral was last exposed to heat or sunlight, can be determined by measuring both the amount of energy trapped in a sample (the equivalent dose) and the rate at which energy was produced by radioactive decay (the dose rate). Similar to U-series, the practical limit of this technique depends on the local dose rate, but is typically on the order of $\sim 100,000$ to 200,000 years (given the low doses rates encountered in the Cyprus samples). The advantage of luminescence methods is that they are among the very few methods that date clastic sediments. A disadvantage of the same methods is that they have low resolution (typically no better than 10\%, sometimes 5\%) and many factors affect accuracy and precision of the ages (Aitken, 1985). Previous workers using luminescence dating on Cyprus samples have reported mixed results, which will be discussed in some detail below.

Where possible, radiocarbon dates were obtained from these deposits, sometimes in conjunction with luminescence samples, as quality control checks, because suitable datable materials utilizing both techniques were not readily preserved in every case. Chronological control is provided by about thirty (30) luminescence ages.

Sediments targeted for optical dating are fine grained colluvium and alluvium, marine sands, and fluvial sand sediments. Samples for optical dating were taken by hammering a $5 \mathrm{~cm}$ interior diameter and 40 to $50 \mathrm{~cm}$ length of PVC tubing into profile walls. These tubes were then wrapped in heavy black photography-style bags before shipment back to the USGS Luminescence Dating Laboratory. The outermost two (2) $\mathrm{cm}$ of sediment inside the tube was removed, leaving non-light exposed sediment in the center of the tube for optical dating. Optical ages were determined by multiple methods on the fine-grained polymineral or fine-sand sized quartz fraction. Initially ages were determined on the fine grained (4-11) polymineral fraction using multiple aliquot techniques (Singhvi et al., 1982; Lang, 1994; Richardson et al., 1997; Forman and Pierson, 2002) with infrared excitation. The fine-grained silt separate of representative samples was isolated and dated using multiple aliquot techniques. Further, selected separates of fine-grained quartz fraction were dated using single aliquot regeneration protocols (Murray and Wintle, 2000; Murray and Wintle, 2003; Wintle and Murray, 2006). Note that optical ages by the two different techniques overlap at one sigma errors and are concordant with radiocarbon or artifact chronologic control.

\section{Sample preparation procedures}

After acid and oxidizer processing, fine grains (4-11 micron) were extracted by suspension settling following Stokes Law after organics and fine sand-sized grains were 
extracted using graduated sieves. Carbonates were removed with soaking in $35 \% \mathrm{H}_{2} \mathrm{O}_{2}$ and in $4 \mathrm{~N}$ $\mathrm{HCl}$, respectively (Aitken, 1998). Quartz extracts on the fine-grained fraction were isolated subsequently by digestion in 50\% hydrofluoric acid (HF) for one hour followed by a brief 10 minute rinse in $8 \mathrm{~N} \mathrm{HCl}$.

It is worth some detail to outline potential problems seen with the mineralogy in the sediment samples from Cyprus. Previous workers (Deckers, 2005, Deckers et al, 2005; Deckers and Fuchs, 2006, 2007; Kinnard et al 2006, Kinnard et al in press, and Spencer et al, 2003) either make no mention of OSL signal stability and component or had no problem with the signals when using SAR. A search for on-line supplemental material associated with the manuscripts was unsuccessful, although an appeal was not made personally to the authors to see if the data could be obtained from them. Most of the samples previously analyzed in these studies were identified as either fluvial or alluvial, and did not include the deltaic or marine terraces or colluvium that this study did, so we are unsure whether the sediment contained the same source geology and mineralogy. As far as we can ascertain, no specifically named deposits have been dated using OSL (i.e. Pachna Fm., Kalavaso Fm., etc) until this manuscript so we could not do a comparison based on the formational diagenesis. Moreover, we found that the samples collected for our study had to follow a fairly elaborate set of preparation procedures before the quartz could be isolated.

A high percentage of the mineral grains in the sediment were olivine, epidote, plagioclase, magnetite (and other heavy minerals), chlorite, or calcite (carbonate). A very low percentage of the grains were quartz (estimates varied from $20 \%$ to $>1 \%$ ) or potassium feldspar (i.e. orthoclase, sanidine, etc.) (see also Figure S7). Some of the remaining quartz grains were slender needle shapes (Figure S6) of quartz that survived acid and HF treatments in some samples, leading us to speculate that they were either sponge or coral spicules or hydrothermal shards of quartz. Some of the sample sites had grains that were intensely coated with calcite, requiring a week or more of 4 to $6 \mathrm{~N} \mathrm{HCl}$ treatment for the break-up and dissolution of the cementing agent. None of the samples were so cemented as to be described as calcarenite, all "flowed" from the tube cleanly. Some samples contained a significant amount of shells that could not be removed completely through visual means or by sieving, since they were about the same size as the desired quartz grains. These samples also required a longer time for $\mathrm{HCl}$ dissolution.

Because the quartz recovery was so very minuscule, at least $300 \mathrm{~g}$ to $400 \mathrm{~g}$ of OSL sample was passed through a Frantz Magnetic Separator after the initial $\mathrm{HCl}$ and $\mathrm{H}_{2} \mathrm{O}_{2}$ procedure had loosened the grains and cleaned them of calcite and clay coatings. Two passes at differing angles and magnetic intensity were required for maximum quartz retention. Often from the $300 \mathrm{~g}$ to $400 \mathrm{~g}$ sample, only one gram or less of usable quartz material was preserved. This tiny amount of quartz was then be subjected to density separation using lithium sodium tungstate (LST) of $2.58 \mathrm{~g} / \mathrm{cm}^{3}$ if microscopic work indicated potassium feldspars were present. Potassium feldspars were not present in a significant number of samples, as can be seen in the low potassium dose rate. After the HF etch and final clean, less than 0.5 to $0.05 \mathrm{~g}$ of pure, etched quartz would remain. This meant that in many cases we were unable to run the minimum required thirty aliquots for acceptable statistics and that many of the preheat and test dose response tests had to be run on only selected samples from each site. This also meant that there was no post-HF etch re-sieve, another reason the Frantz Magnetic Separator became an invaluable lab tool for winnowing out heavy minerals and plagioclase. In a few cases no quartz remained, thus no quartz OSL ages are presented. 
For the multiple aliquot polymineral silt procedure an ethanol silt slurry was deposited on the grains, the alcohol dried, and the silt deposited as a thin layer over the entire disc (about one $\mathrm{cm}$ in diameter). Because many samples had low potassium content, and thus low potassium feldspars, the infrared-stimulated signal (IRSL) was too dim to be measured in some cases. IRSL dating was not attempted unless the elemental concentrations showed potassium contents of $0.50 \%$ or above. For the single aliquot regeneration OSL analysis, sub-samples of grains from the etched quartz fraction were mounted as a monolayer on a one $\mathrm{cm}$ diameter aluminum disc using Silkospray ${ }^{\mathrm{TM}}$ silicone oil. The grains were adhered using a four mm diameter mask, which covered a little less than half of the disc surface area. This coverage is considered to be a “medium aliquot” containing perhaps 150 to 200 grains.

\section{Multiple aliquot regeneration procedures}

Multiple-aliquot additive dose (MAAD) procedures with component dose normalization (Singhvi et al., 1982; Lang, 1994; Richardson et al., 1997; Forman and Pierson, 2002) were used in this study to estimate the equivalent dose on fine-grained polymineral fraction from sediments (Table S3). Low emissions ( $<200$ counts/sec) at or near the background counts with subsequent infrared excitation was measured. Solar resetting of aliquots prior to MAAD analysis was accomplished by eight hour illumination using natural sunlight, removing any pre-existing electrons within accessible photosensitive traps while inducing minimal dose sensitivity changes (Richardson, 1994). Luminescence was measured using a Daybreak 1100 Luminescence Reader with Schott BG-39 filters coupled to an EMI 9235 QA Photomultiplier tube containing light emitting diodes capable of infrared $(880 \pm 30)$ excitation. Further details are in Table S1.

Equivalent doses were calculated for at least the first 30 seconds of excitation, dependent on background counts, as a weighted mean (Table in manuscript). The silt was preheated using a long, slow temperature of $124{ }^{\circ} \mathrm{C}$ for 64 hours. A minimum of two analyses per IRSL sample by MAAD methods was performed. Anomalous fading tests on the stability of the luminescence signal indicated little to no signal instability (recording ratios of 0.93 to 1.03 for a fade ratio of only three to seven percent, Huntley and LaMothe, 2001 ). This was surprising, since the potassium feldspar is assumed to come from pillow lavas or other volcanic sources that are often known to fade. Growth curve data was fit to an exponential trend. All samples were analyzed using continuous wave (CW-OSL) stimulation.

\section{Single aliquot regeneration protocols}

An automated Risø TL/luminescence-DA-15 system was used for SAR analyses and continuouswave (CW) OSL was used. Further details are in Table S2. Single aliquot regeneration (SAR) protocols (Murray and Wintle, 2000; Murray and Wintle, 2003; Wintle and Murray, 2006) were used in optical dating of fine grained quartz separates (Table S4). The natural and regenerated signals were all fairly bright, weren’t close to background, and didn’t look “dim”.

However, the luminescence emissions for a large majority of the quartz samples showed a mixed dominance of either a slow or medium component instead of the fast component (Murray and Wintle, 2003), often one signal or the other would appear on differing aliquots of the same sample when continuous-wave (CW) OSL was employed (Figure S8, Figure S9, Figure S10, and Figure S11). The emissions had a $>95 \%$ diminution of luminescence after four seconds of excitation with blue light (Figure S8). The thermal stability of the medium component was researched (Figure S10) and found to be unstable whenever the curves did not show a clear, unambiguous fast signal. 
All SAR emissions were integrated over the first 0.8 seconds (s) of stimulation out of 40 s of measurement, with background based on emissions for the last 30- to 40-s interval. The misshapen growth of some of the decay curves was not caused from feldspar contamination for three reasons: lack of potassium feldspars in the samples, no signal was produced from IR stimulation, and lack of any contaminations noted in routine microscopic checks on grains from sample aliquots. Five checks were performed on the samples (one sample from each site or deposit was used as a proxy for the others due to low quartz content).

1). Appropriate preheat: there were two difficulties in choosing an appropriate preheat. There was evidence of recuperation (see growth curve on Figure S10) on samples that were young (e.g. 11/18/09-2 at $900 \pm 230$ years) which would normally be mollified with less stringent preheats of $200{ }^{\circ} \mathrm{C}$ to $220^{\circ} \mathrm{C}$. However, preheat test showed using temperatures of 260 ${ }^{\circ} \mathrm{C}$ to $280{ }^{\circ} \mathrm{C}$ actually produced slightly more stable results than the lower temperatures. A series of experiments was performed to evaluate the effect of preheating at $180{ }^{\circ} \mathrm{C}, 200{ }^{\circ} \mathrm{C}, 220^{\circ} \mathrm{C}$, $240{ }^{\circ} \mathrm{C}, 260{ }^{\circ} \mathrm{C}, 280^{\circ} \mathrm{C}$ and $300^{\circ} \mathrm{C}$ on thermal transfer of the regenerative signal prior to the application of SAR dating protocols (Murray and Wintle, 2003). These experiments showed some preheat-based sensitivity changes as the temperature approached $300{ }^{\circ} \mathrm{C}$ or higher or any heat below about $220^{\circ} \mathrm{C}$. Based on these choices samples that were considered to be younger than about 5,000 years had a preheat and a cut heat of $220^{\circ} \mathrm{C}$ and samples that were older were run with a $260{ }^{\circ} \mathrm{C}$ or $280{ }^{\circ} \mathrm{C}$ preheat.

2). Dose reproducibility response: A test for dose reproducibility was also performed (Murray and Wintle, 2003) with the initial and final regenerative dose of 7.1 Gy yielding concordant luminescence response (at 1-sigma error) (Fig. S8).

3). Recycling ratio: Sensitivity changes were calculated as a response to Lx/Tx (See table S4). This recycling ratio must be consistent with unity (within $1.0 \pm 0.1$ ) if the program dose-response curves are measuring stable signals. Normally if the recycling ratio is not consistent with 0.9-1.1 within errors, then the aliquot will be rejected. Failure of this test shows that the sensitivity correction applied to the regeneration signals is not working adequately. The Cyprus samples with a medium component did not pass the unity tests, unless the range was adjusted more widely to 0.8-1.2.

4). Assessment of recuperation: Recuperation is identified by the measurement of the response to a "zero" dose (0 Gy) administered both prior to the first and the recycled beta doses. The measurement should give a negligible OSL signal, however in some instances high levels of OSL recuperation have been reported (e.g. Steffan et al, 2009). The phenomenon is often observed in young samples examined using high preheat temperatures, where charge is released from thermally unstable traps into optically sensitive traps, and then released on optical stimulation (Bailey et al., 2003; Steffen et al., 2009; Wintle and Murray, 2006). This readjustment is attributed to recuperation in the measured OSL signal being derived from more than just the fast component, and it is suggested that a high temperature $\left(280^{\circ} \mathrm{C}\right)$ optical stimulation following measurement of the test dose could be used to minimize the effect of recuperation.

5). Presence of a "fast component" of OSL decay: One of the key requirements for successful OSL dating of quartz using the standard SAR procedure is the presence of a "fast" component (Wintle and Murray, 2006). The OSL signal from quartz is known to consist of a number of discrete components which decay at different rates under optical stimulation in the laboratory (e.g. Bailey et al., 2003; Bulur, 1996; Jain et al., 2003; Singarayer and Bailey, 2003). While the OSL signal from some samples of quartz have been found to contain up to seven 
components (Jain et al., 2003), the majority of samples have between three and five components. The components are ultrafast, fast, medium, slow1, slow2, slow 3, and slow4.

The fast component has the most rapid rate of decay, and hence bleaches fastest both under stimulation in the laboratory and during exposure to sunlight in nature; this makes it the most desirable component for use in OSL dating because it will retain the smallest residual charge. Additionally, the fast component has been shown to be most thermally stable (Bulur, 1996; Singarayer and Bailey, 2003; Li and Li, 2006). This component is commonly found in the vast majority of quartz samples (except those from Cyprus, New Zealand, and the Andes region), and the SAR measurement procedure was developed on samples with a dominant fast component.

When the fast component is not dominant in the part of the decay curve used for $\mathrm{D}_{\mathrm{e}}$ calculation, problems often arise with age under-or over-estimation (e.g. Choi et al., 2006; Steffen, 2009). Various methods to overcome this problem have been suggested in the literature. These include curve fitting to isolate the fast component where a large proportion of the OSL signal consists of medium and slow components, or a more stringent cut-heat temperature (e.g. 200 or $220^{\circ} \mathrm{C}$ rather than the originally proposed $160^{\circ} \mathrm{C}$ ) may be required if an ultra-fast component is present (Murray and Wintle, 2003).

Another simple test for determining whether the signal is dominated by the fast component is accessing whether a simple exponential or exponential and linear function is able to be fitted to the $\mathrm{L}_{X} / \mathrm{T}_{X}$ points in order to form a growth curve. If not, the aliquot should be rejected (i.e. Figure S8 is fitted to a cubic function). This could also occur when low signal levels are present but there were very few samples that had low signals.

\section{Dose rate determination}

To render an optical age, the environmental dose rate is needed, which is an estimate of sediment exposure to ionizing radiation from the decay of the $U$ and Th series and ${ }^{40} \mathrm{~K}$ (sometimes including ${ }^{87} \mathrm{Rb}$ ), and cosmic sources during the burial period (see tables in manuscript). The $U$ and Th content of sediment, assuming secular equilibrium in the decay series, were determined by inductively coupled plasma mass spectrometry analyzed at the U.S. Geological Survey (Denver, CO) as well as by high resolution gamma spectrometry (Ge detector) also USGS, Denver for a small comparative set of samples (Table S5). The majority of samples were analyzed only by high-resolution gamma spectrometry. The cosmic ray components of 0.22 to $0.14 \mathrm{mGy} / \mathrm{yr}$ (appropriate to depth and elevation) were included in the estimated dose rate (Prescott and Hutton, 1994). These cosmic components were not non-trivial and accounted for up to 40 percent of the dose rate in one or two cases. The majority of samples had cosmic dose components that added up to at least 10 to 20 percent of the dose rate, mainly due to the shallow depth of the samples and the low total environmental elemental concentrations that made up the dose rate.

The moisture content, as measured in the field, was not used to calculate the dose rate for three reasons: the moisture was not adequately preserved during shipment of the samples, nor was it recorded in the field, and for samples older than Pleistocene or known to have been saturated by local water tables for periods of time, the field moisture would be a wildly inaccurate estimate of the amount or time of water infiltration. Our solution to this problem was to measure a complete saturation moisture content for each sample (that is, simulate how much water the sample could hold in pore spaces during immersion and centrifuging in water) and then take half of the total moisture conditions for sediments (i.e. if total moisture content was 30 
percent, then dose rate was calculate with 15 percent of the moisture). If there was no doubt that the particular sampling site had been below water table for a significant portion of time, we applied a 90 percent total moisture content to the dose rate calculation (i.e. if the total moisture content was four percent then we took $0.90 * 45=40.5$ percent as the content to use when calculating the dose rate).

Because of the post depositional additions and inhomogeneous nature of the deposits from which the samples in this study were taken, it was difficult to accurately determine the gamma flux of the sediments from laboratory measurements alone. Unfortunately, there was no measurement of the field gamma spectrometry to determine the in-situ gamma dose-rate, as the OSL specialist did not visit any of the sites personally. Therefore, we are aware that our best guess approximation may not capture both the large-and small-scale variability in the dose rate at each sample location. It would be instructive to compare our laboratory dose rate data with any field data from other studies on Cyprus, but we were unable to find this data in an on-line literature search.

Assessment of the dose rate for these samples is also extremely complex, because some of the grains were coated with calcite and clay over time and the dose rate to the sediment grains is likely therefore to have changed over time. There was also very low $U$ and Th concentrations in the system (see table with elemental concentrations in the manuscript, typically U averaged about $0.45 \mathrm{ppm}$ and Th averaged about $1.0 \mathrm{ppm}$ ). Occasionally, samples would show equal amounts of U/Th (sample \#11/19/09-8) or a higher U than Th reading (sample \# 11/18/09-2). This indicates groundwater movement and redistribution of Th through sediment and a high likelihood of disequilibria in the uranium-and thorium-decay series. For these reasons, such samples would not normally be considered for routine luminescence dating, and the accuracy of the luminescence ages generated for some of these Cypriot samples cannot be verified and so ages should be taken as indicative only. We did go to some lengths to verify which samples may have had disequilibrium problems by comparing the elemental concentrations as measured from two different methods (ICP-MS and gamma spectrometry) and for different periods of time (instantaneous measurement vs. a three week delay in gamma spectrometry values, table S5). We found, in general, that there was little disequilibrium and in every case when there was disequilibrium the sample had already been rejected for equivalent dose problems.

Dose rates are listed for IRSL and quartz OSL in tables in this supplement. For the corresponding quartz OSL dose rates, the alpha component, as well as about $10 \%$ of the beta component, must be subtracted, due to the HF etch performed on the quartz grains before they were analyzed for OSL. Alpha and beta contributions to the dose rate were corrected for grainsize attenuation (Aitken, 1985). The alpha efficiency for the silt-sized samples was determined by comparing MAAD-alpha source exposed and MAAD-beta source exposed curves, using approaches in Aitken (1985).

Where possible, sampling sub-sets (multiple small samples around an OSL site) were compared against each other in order to detect these inhomogeneous geologic conditions (i.e. large stones, clay layers, or cementation) as well as to fully account for any gamma activity that the OSL sample received from layers above and below that might have had differing grain size or geologic source. For this purpose the bulk samples were dried, homogenized by gentle disaggregation, weighed, sealed in plastic planchets having a diameter of $15.2 \mathrm{~cm}$ by $3.8 \mathrm{~cm}$ (some modification from Murray et al., 1987, Snyder and Duval, 2003), and then immediately placed in a gamma-ray spectrometer for an 8.5 hour count. Samples were then stored for a minimum of 21 days to allow radon to achieve radioactive equilibrium, and the measurements 
were repeated. The fraction of radon emanation was estimated from the difference of these two spectrometer measurements. A sealed/unsealed ratio of $<1.10$ is not considered to represent significant radon escape under laboratory conditions. These count rates are accurate for calculating dose rates.

\section{Summary}

Of the forty-five samples prepared and submitted for analyses, only two-thirds of the samples managed to pass a majority of the tests (7 out of 9 ) for acceptable age determinations. Failures included dose rates that showed disequilibrium problems, a missing fast OSL component, no quartz or very little quartz, equivalent dose values that were scattered due either to incomplete bleaching, and/or problems of inhomogeneous microdosimetry (see radial plots Figures S12 through S14 where I have showed a worst case scenario, a moderate case of dispersion, and the best case scenario). If the quartz OSL was questionable and there was no other method to check against (IRSL, radiocarbon, archeology, or U-series) then the age is listed as indicative only (i.e. $>30 \mathrm{ka}$ or as $\sim 30 \mathrm{ka}$ ).

In many cases the IRSL ages compare well with the quartz OSL ages (i.e. sample 11/19/09-4: Quartz OSL $2.38 \pm 0.32$ ka vs. IRSL $2.94 \pm 0.19 \mathrm{ka}$ ), although there were notable discrepancies (i.e. 11/18/09-6: Quartz OSL 14.6 \pm 1.33 ka vs IRSL at 19.2 $\pm 1.61 \mathrm{ka}$ ). Where there was doubt about the quartz OSL and if there was sufficient K-spar to run IRSL analyses, the IRSL often showed older ages (i.e. 11/18/09-2 and 1/18/09-6). This is not unexpected for two reasons. The quartz may be considerably underestimating the true age, as Steffen et al., 2009 found the same problem in quartz with a dominant medium component or the K-spar may be overestimating the true age as it is considered to take more time to bleach than quartz.

\section{References}

Aitken, M.J., 1985, Thermoluminescence Dating, London, Academic Press, 359 p.

Aitken, M.J. (1998). An Introduction to Optical Dating: The dating of Quaternary sediments by the use of photon-stimulated luminescence. Oxford University Press, New York, 267 pp.

Bailey, R.M., J. S. Singarayer, S. Ward, S. Stokes, 2003, Radiation Measurements 37, 511.

Bulur, E., 1996, An alternative technique for optically stimulated luminescence (OSL) experiments. Radiation Measurements 26, 701-709.

Choi, J.H., Duller, G.A. T., and Wintle, A.G., 2006, Analysis of quartz LM-OSL curves. Ancient TL, vol. 24, no. 1, p. 9-20.

Deckers, K., 2005. Post-Roman history of river systems in Western Cyprus: Causes and archaeological implications. Journal of Mediterranean Archaeology, Vol 18, No.2, no pp.

Deckers, K., Sanderson, D.C.W. and Spencer, J.Q.C., 2005, Thermoluminescence Screening of NonDiagnostic Sherds from Stream Sediments to Obtain a Preliminary Fluvial Chronology: An Example from Cyprus. Geoarchaeology. An International Journal 20.1, 2005. 
Deckers, K. and Fuchs, M. (Eds), 2007, Proceedings of the Eastern Mediterranean/Near Eastern Geoarchaeology Meeting.Part II. Geoarchaeology. An International Journal. Volume 22.6.

Forman, S.L., and Pierson, J., 2002, Late Pleistocene luminescence chronology of loess deposition in the Missouri and Mississippi river valleys, United States, Palaeogeography, Palaeoclimatology, Palaeoecology, v. 186, no. 1 and 2, p. 25-46.

Fuchs, M. and Deckers, K. (Eds), 2006, Proceedings of the Eastern Mediterranean/Near Eastern Geoarchaeology Meeting. Geoarchaeology. An International Journal. Volume 21.7.

Galbraith, R.F., Roberts, R.G., Laslett, G.M., Yoshida, H. and Olley, J.M., 1999, Optical dating of single and multiple grains of quartz from Jinmium rock shelter, Northern Australia: Part I, Experimental Design and Statistical Models. Archaeometry, 41 (2), 339-364.

Huntley, D. J., and Lamothe, M., 2001, Ubiquity of anomalous fading in K-feldspars and the measurement and correction for it in optical dating: Canadian Journal of Earth Sciences, v. 38, p. 1093-1106.

Jain, M., L. Botter-Jensen, A. K. Singhvi., 2003, Rad. Meas. 37, 67.

Kinnaird, T.C., Sanderson, D.C.W., Burbidge, C., Robertson, A.H.F., Panayides, I., Tsiolakis, E. and Zomeni, Z., 2006. Optically stimulated luminescence: A means of dating neotectonism in southern Cyprus? UK luminescence and ESR dating research meeting, University of Liverpool.

Kinnaird, T.C., Sanderson, D.C.W., Burbidge, C. and Peltenburg, E. 2011? In press?. OSL dating of Neolithic Kissonerga-Mylouthkia, Cyprus. Neo-lithics

Murray, A.S., Marten, R., Johnston, A., and Martin, P., 1987, Analysis for naturally occurring radionuclides at environmental concentrations by gamma spectrometry, Journal of Radioanalytical and Nuclear Chemistry, Article 115, p. 263-288.

Murray, A.S., and Wintle, A.G., 2000, Luminescence dating of quartz using an improved single-aliquot regenerative-dose protocol, Radiation Measurements, v. 32, no. 1, p. 57-73

Prescott, J.R. and Hutton, J.T., 1988, Cosmic ray and gamma ray dosimetry for TL and ESR, Nuclear Tracks and Radiation Measurements v. 14, p. 223-230.

Prescott, J. R. and Hutton, J.T., 1994, Cosmic ray contributions to dose rates for luminescence and ESR dating: large depths and long-term time variations, Radiation Measurements, v. 23, p. 497-500.

Richardson, C.A., McDonald, E.V. and Busacca, A.J., 1997, Luminescence dating of loess from the northwest United States, Quaternary Science Reviews, v. 16, no. 3-5, p. 403-415.

Richardson, C.A., 1994, Rad. Meas, 23, 587.

Singarayer, J.S., R. M. Bailey, 2003, Rad. Meas. 37(4-5) 451-458.

Singhvi, A.K., Sharma, Y.P. and Agrawal, D.P., 1982, Thermo-Luminescence Dating of Sand Dunes in Rajasthan, India, Nature, v. 295 (5847), p. 313-315. 
Singhvi, A.K., Bluszcz, A., Bateman, M.D ,and Rao, M.S., 2001, Luminescence dating of loess-palaeosol sequences and cover sands: methodological aspects and palaeoclimatic implications, Earth-Science Reviews, v. 54, no. 1-3, p. 193-211.

Snyder, S.L., and Duval, J.S., 2003, Design and construction of a Gamma-ray Spectrometer system for determining natural radioactive concentrations in geological samples at the U.S. Geological Survey in Reston, Virginia,: U.S. Geological Survey Open-File Report 03-29 (on-line only) (http://pubs.usgs.gov/of/2003/of03-029/).

Spencer, J.Q.; Sanderson, D.C.W.; Deckers, K. and Sommerville, A. 2003. Assessing Mixed Dose Distribution in Young Sediments identified using Small Aliquots and a Simple Two-Step SAR Procedure: The F-Statistic as a Diagnostic Tool, Radiation Measurements 37, 425-431.

Steffen, D., Preusser, F., and Schlunegger, F., 2009, OSL quartz age underestimation due to unstable signal components, Quaternary Geochronology 4, 353-362.

Wallinga, J., 2002. Optically stimulated luminescence dating of fluvial deposits: a review. Boreas 31 (4), 303-322. 


\section{TABLE S1: Luminescence parameters used in preparation and analyses of samples for IRSL}

Measurement parameters:

Machine Daybreak 1100 Luminescence Reader

Mineral; grain size:

polymineral: 4-11 $\mu \mathrm{m}$

Stimulation source:

20 IR diodes, emission centered on $880 \mathrm{~nm}$

Power delivered to aliquot:

$100 \mathrm{~mW} / \mathrm{cm}^{2}$ (full strength)

Duration of stimulation:

30 seconds

Final signal level:

$10 \%$ of initial

Photomultiplier:

EMI 9235QA quartz window bialkali

Aliquot temperature:

$30{ }^{\circ} \mathrm{C}$

Detection filters:

Schott BG-39 + Corning 7-59 (blue)

Normalization:

natural (0.5 sec at reduced voltage)

Preheat:

$124{ }^{\circ} \mathrm{C}$ for 64 hours

Delay before measurement:

$24 \mathrm{hr}$ or more

Equivalent dose evaluation: additive method using integrated OSL/ satisfactory plateau

Background evaluation:

after bleaching with natural sunlight and quartz window

Alpha effectiveness:

fine grains: $\mathrm{a}=0.07-0.09$

Dose-rate evaluation:

lab gamma spectrometer (NaI earlier samples and Ge later samples), ICP-MS

Dose rate range:

0.63-2.10 Gy/ka (average 1.10 Gy/ka)

Water content:

$10-30 \%$

Cosmic-ray contribution:

$30 \%$ of total dose rate for some near surface samples, $10-20 \%$ average 


\section{TABLE S2: Luminescence parameters used in preparation and analyses of samples for quartz OSL}

Measurement parameters:

Automated Risø TL/luminescence-DA-15

Mineral; grain size:

quartz: $250-180 \mu \mathrm{m}$ or $180-90 \mu \mathrm{m}$

Stimulation source:

blue LED diodes, emission centered on $470 \mathrm{~nm}$

Power delivered to aliquot:

$13 \mathrm{~mW} / \mathrm{cm}^{2}$ (90\% power)

Duration of stimulation:

40 seconds

Final signal level:

$1 \%$ of initial

Photomultiplier:

Thorn-EMI 9235Q

Aliquot temperature:

$125{ }^{\circ} \mathrm{C}$

Detection filters:

two Hoya U340 filters

Normalization:

none

Preheat:

$240{ }^{\circ} \mathrm{C}$ (samples $<5 \mathrm{ka}$ ) and $280{ }^{\circ} \mathrm{C}$ ( $>5 \mathrm{ka}$ ) for $10 \mathrm{secs}$

Delay before measurement:

$120 \mathrm{sec}$

Equivalent dose evaluation: single aliquot regeneration (Murray and Wintle, 2000)

Background evaluation:

black body counts $<35 \mathrm{ct} / \mathrm{sec}$, BG counts $<40 \mathrm{ct} / \mathrm{sec}$

Alpha effectiveness:

n/a

Dose-rate evaluation:

lab gamma spectrometer (NaI earlier samples and Ge later samples), ICP-MS

Dose rate range:

0.46-1.69 Gy/ka (average 0.75 Gy/ka)

Water content:

$10-30 \%$

Cosmic-ray contribution: 
Table S3: Multiple Aliquot Regenerative Dose Procedure.

1. Beta irradiation of sets of discs (4 in a set), doubling the dose for each successive set. Second set is kept close to expected dose from the natural

2. Bleaching of a set of discs for 8 hours (or longer) by exposure to natural sunlight

3. 24 hour delay

4. All discs, including set of naturals, put into preheat $124{ }^{\circ} \mathrm{C}$ for 64 hours

5. 24 hour delay

6. Stimulation with infrared and data collection

Table S4. Single Aliquot Regeneration Protocol for Optical Dating.

1. Preheat $\left(200-240^{\circ} \mathrm{C}\right)$ for 10 seconds (preheat range is specific to Cyprus samples)

2. OSL stimulation with blue light $(470 \mathrm{~nm})$ at $125^{\circ} \mathrm{C}$ for 40 seconds $\left(\mathrm{L}_{\mathrm{n}}\right)$

3. Test dose beta irradiation

4. Cut heat (same temp as preheat) for $0 \mathrm{sec}$

5. OSL stimulation with blue light $(470 \mathrm{~nm})$ at $125^{\circ} \mathrm{C}$ for 40 seconds $\left(T_{n}\right)$

6. Beta irradiation of regeneration dose

7. Preheat $\left(200-240^{\circ} \mathrm{C}\right)$ for 10 seconds

8. OSL stimulation with blue light $(470 \mathrm{~nm})$ at $125^{\circ} \mathrm{C}$ for 40 seconds $\left(L_{x}\right)$

9. Test dose beta irradiation

10. Cut heat (same temp as preheat) for $0 \mathrm{sec}$

11. OSL stimulation with blue light $(470 \mathrm{~nm})$ at $125^{\circ} \mathrm{C}$ for 40 seconds $\left(T_{x}\right)$

12. Repeat Steps 6-11 with further regeneration doses 
Table S5. Comparison of gamma spectrometry and ICP-MS elemental concentration data for several samples within the same vicinity.

\begin{tabular}{|c|c|c|c|c|c|}
\hline Sample & $\mathrm{K}(\%)^{\mathbf{b}}$ & $\mathrm{U}(\mathrm{ppm})^{\mathrm{b}}$ & Th (ppm) & $\begin{array}{c}\text { Cosmic } \\
\text { dose }^{c}\end{array}$ & Total Dose \\
\hline information & & & & $\begin{array}{c}\text { additions } \\
\text { (Gy/ka) }\end{array}$ & Rate (Gy/ka) \\
\hline $2 / 23 / 10-1$ & $0.64 \pm 0.05$ & $0.31 \pm 0.02$ & $0.71 \pm 0.05$ & $0.22 \pm 0.02$ & $0.90 \pm 0.04$ \\
\hline \multirow[t]{3}{*}{$3 / 1 / 10-3$} & $0.40 \pm 0.02$ & $0.63 \pm 0.04$ & $0.79 \pm 0.06$ & $0.22 \pm 0.02$ & $0.75 \pm 0.03$ \\
\hline & $0.45 \pm 0.03^{\mathrm{c}}$ & $0.68 \pm 0.04^{\mathrm{c}}$ & $0.68 \pm 0.06^{c}$ & - & - \\
\hline & $0.79 \pm 0.07^{\mathrm{d}}$ & $0.32 \pm 0.02^{\mathrm{d}}$ & $0.66 \pm 0.10^{\mathrm{d}}$ & - & $1.01 \pm 0.05^{\mathrm{d}}$ \\
\hline \multirow[t]{3}{*}{$3 / 1 / 10-4$} & $0.28 \pm 0.01$ & $0.23 \pm 0.03$ & $0.33 \pm 0.06$ & $0.22 \pm 0.02$ & $0.52 \pm 0.03$ \\
\hline & $0.32 \pm 0.02^{\mathrm{c}}$ & $0.27 \pm 0.02^{\mathrm{c}}$ & $0.28 \pm 0.05^{\mathrm{c}}$ & - & - \\
\hline & $0.61 \pm 0.05^{\mathrm{d}}$ & $0.18 \pm 0.02^{\mathrm{d}}$ & $0.18 \pm 0.03^{\mathrm{d}}$ & - & $0.77 \pm 0.05^{\mathrm{d}}$ \\
\hline \multirow[t]{3}{*}{$3 / 2 / 10-3$} & $1.00 \pm 0.02$ & $1.08 \pm 0.06$ & $0.94 \pm 0.08$ & $0.22 \pm 0.02$ & $1.34 \pm 0.04$ \\
\hline & $0.32 \pm 0.02^{\mathrm{c}}$ & $0.27 \pm 0.02^{\mathrm{C}}$ & $0.28 \pm 0.05^{c}$ & - & - \\
\hline & $0.51 \pm 0.05^{\mathrm{d}}$ & $0.70 \pm 0.04^{\mathrm{d}}$ & $1.76 \pm 0.09^{\mathrm{d}}$ & - & $0.92 \pm 0.05^{\mathrm{d}}$ \\
\hline
\end{tabular}

${ }^{\mathrm{b}}$ Analyses obtained using laboratory Gamma Spectrometry (high resolution Ge detector) and readings are delayed after 21 days of being sealed in the planchet (used for dose rates).

${ }^{\mathrm{c}}$ Analyses obtained using laboratory Gamma Spectrometry (high resolution Ge detector) and readings are immediately following being sealed in planchet.

${ }^{\mathrm{d}}$ Analyses obtained using inductively coupled mass spectrometry (ICP-MS). 


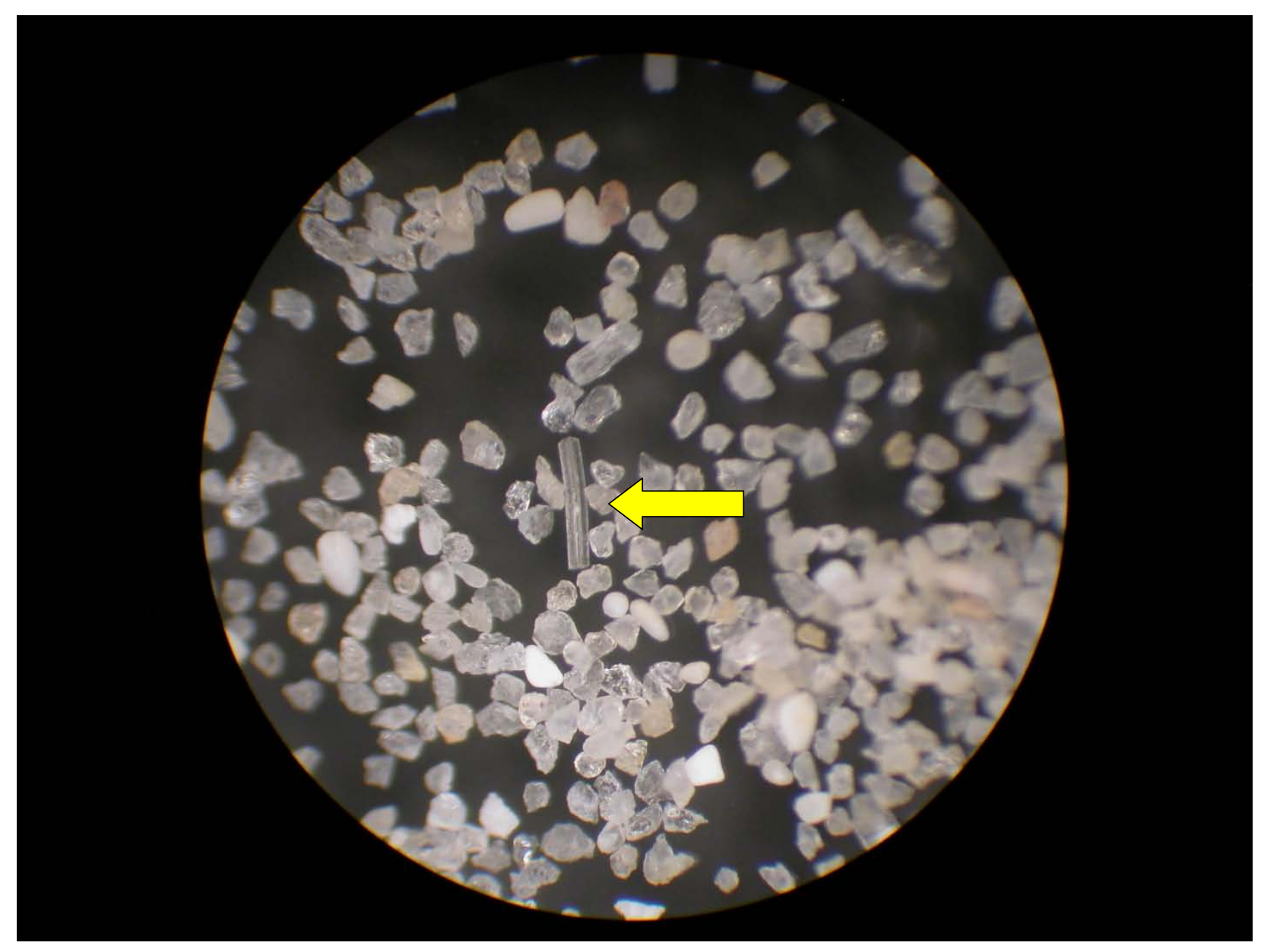

Figure S6. Picture of a quartz spicule as seen in sample 11/18/09-2 (middle of picture). These spicules have been through all acid treatments, including HF. The grain size is 180-90 microns and the edges are blurry due to an incorrect F-stop exposure. 


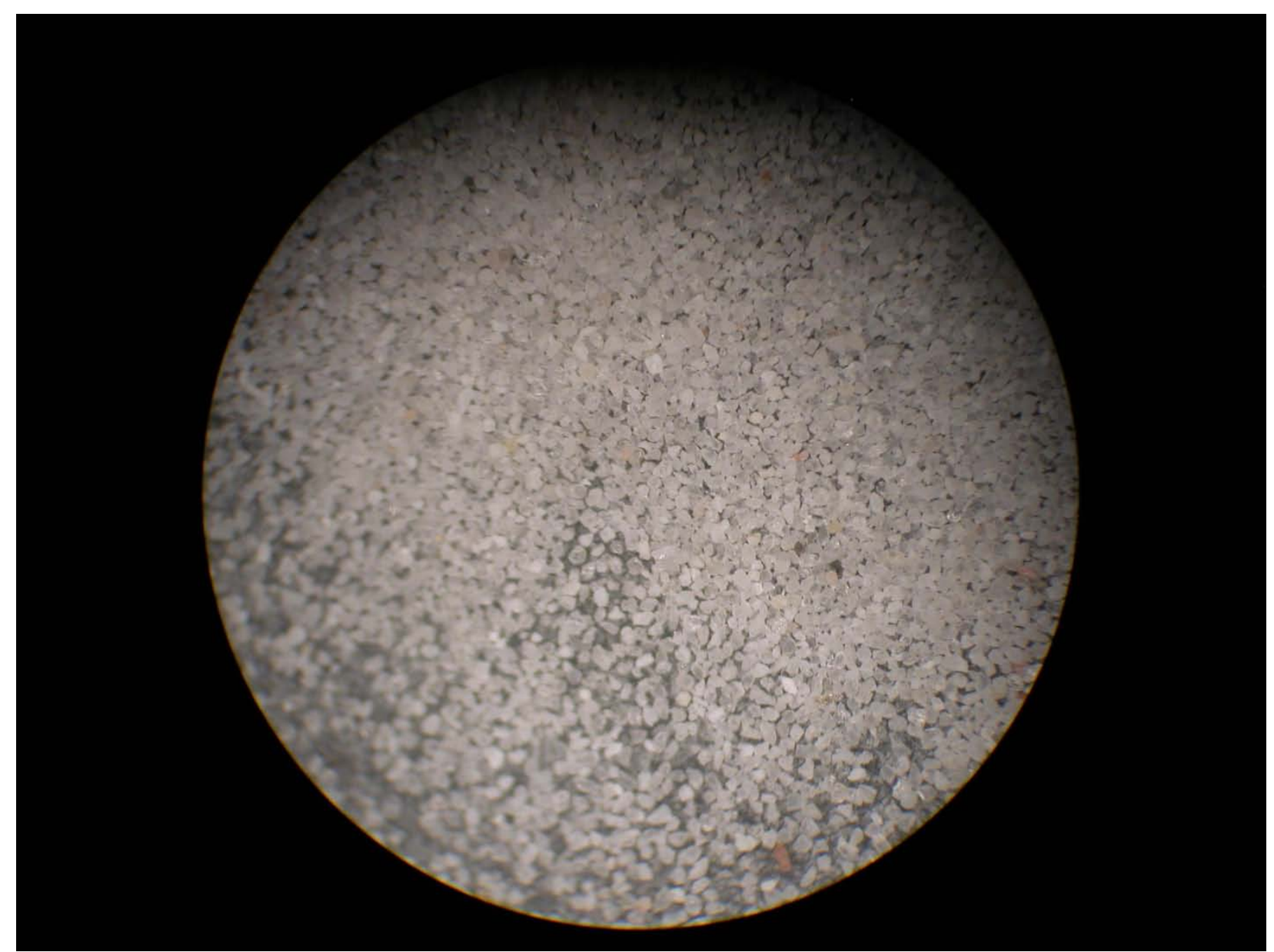

Figure S7. Picture of cleaned, etched quartz from sample 3/1/10-3. The grain size is 180-90 microns and the edges are blurry due to an incorrect F-stop exposure. 


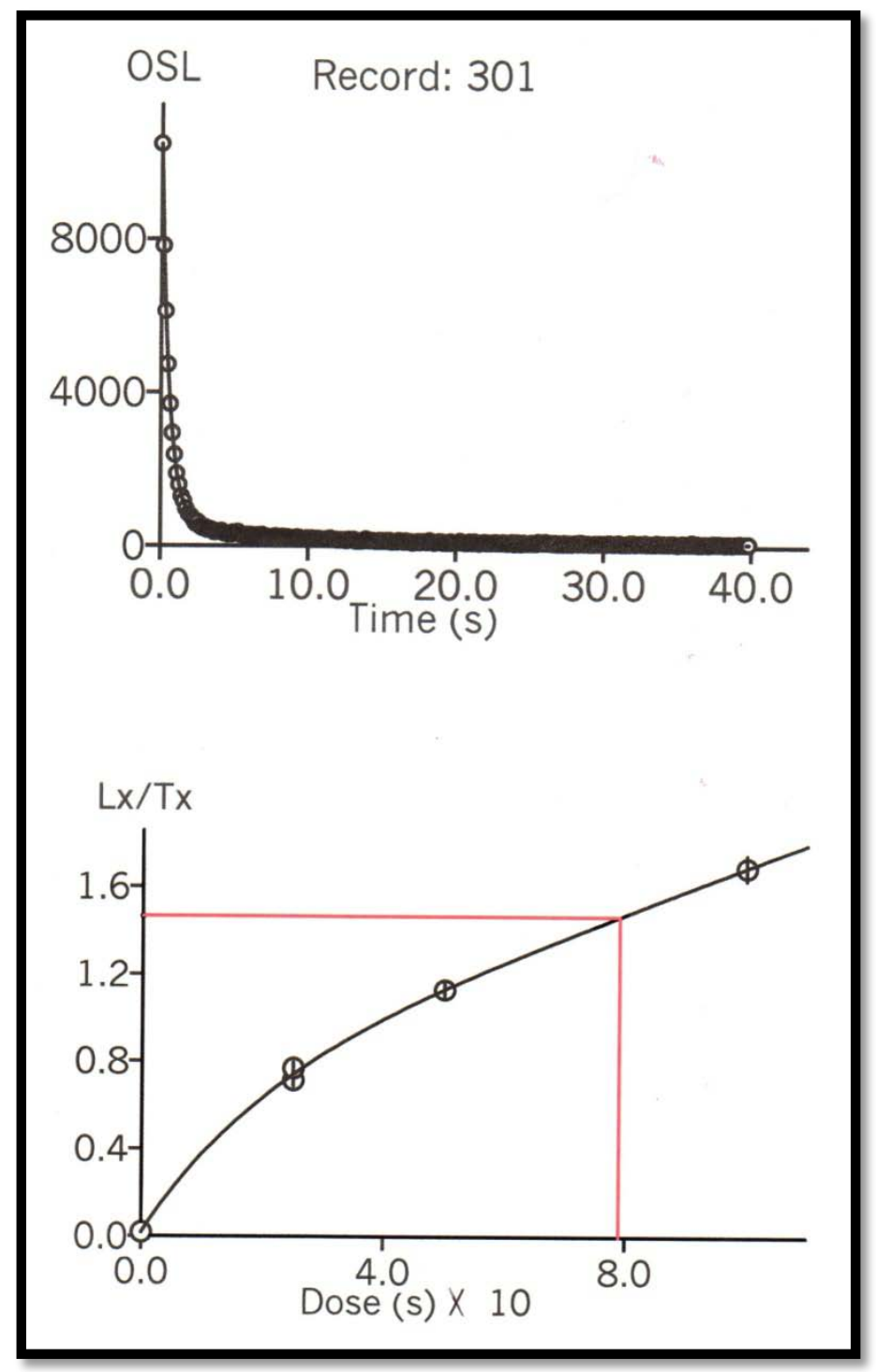

Figure S8. Plot of $L_{X} / T_{X}$ values as a function of regenerated dose expressed in seconds of exposure to a laboratory beta radiation source. The beta source delivered $\sim 0.079$ to $0.071 \mathrm{~Gy} / \mathrm{s}$ to these coarse-grains mounted on aluminum discs (Grays change because of the length of time between sample analyses, in some cases several years). A dose-response curve is fitted through the points and the intercept of the $\mathrm{L}_{\mathrm{N}} / \mathrm{T}_{\mathrm{N}}$ value is used to obtain a $\mathrm{D}_{\mathrm{e}}$ value (in seconds, and hence then in Gy) for the aliquot. This decay and growth curve show a "best case" scenario for Cypriot samples (11/21/09-9) with a clear fast OSL component fitted to an exponential + linear curve. 


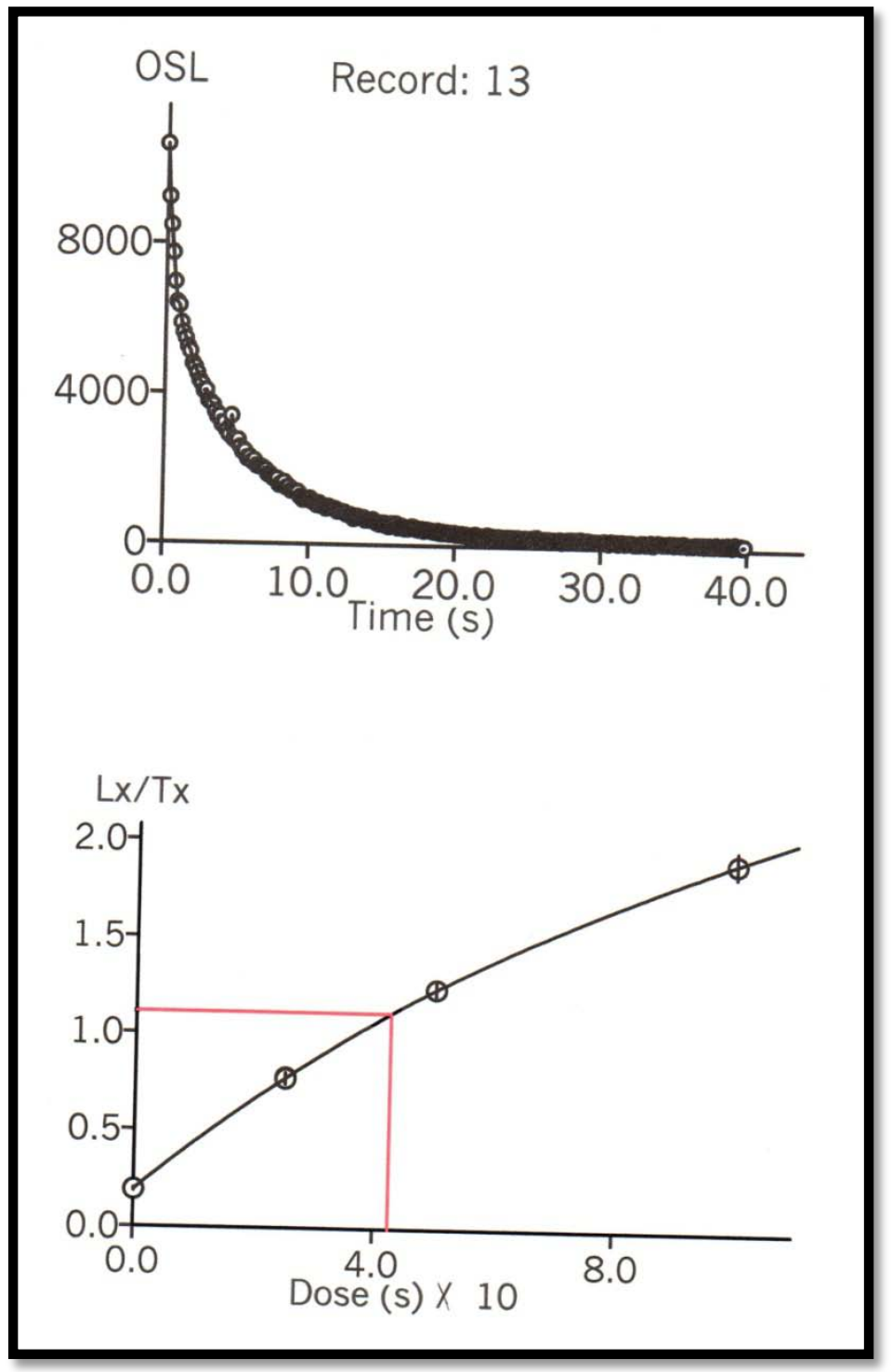

Figure S9. Plot of $L_{X} / T_{X}$ values as a function of regenerated dose expressed in seconds of exposure to a laboratory beta radiation source. The beta source delivered $\sim 0.079$ to $0.071 \mathrm{~Gy} / \mathrm{s}$ to these coarse-grains mounted on aluminum discs (Grays change because of the length of time between sample analyses, in some cases several years). A dose-response curve is fitted through the points and the intercept of the $\mathrm{L}_{\mathrm{N}} / \mathrm{T}_{\mathrm{N}}$ value is used to obtain a $\mathrm{D}_{\mathrm{e}}$ value (in seconds, and hence then in Gy) for the aliquot. This decay and growth curve show a "worst case" scenario (3/12/2002-1) for Cypriot samples with a misshapen decay curve and obvious recuperation at the "zero" point. 


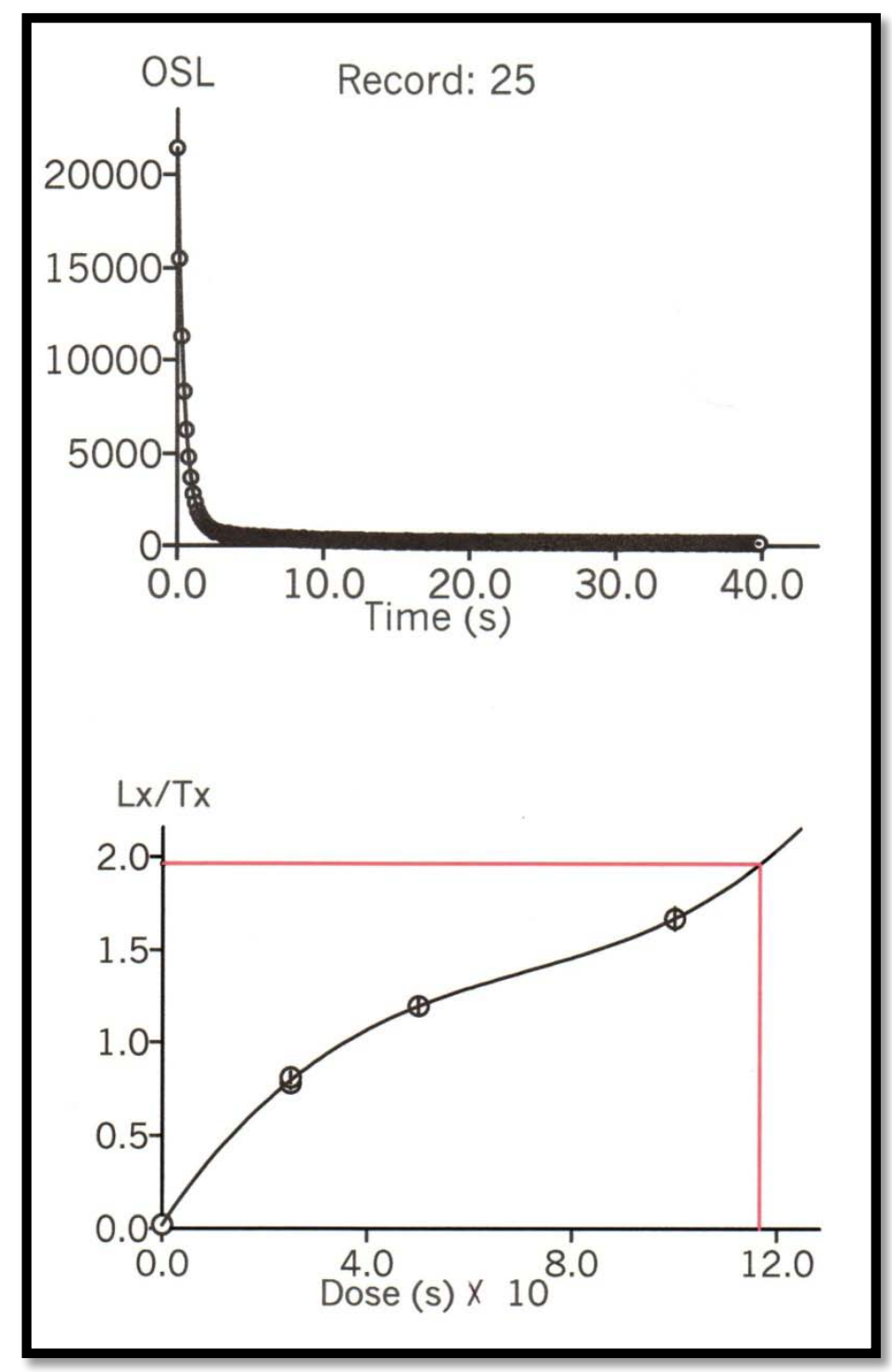

Figure S10. Plot of $L_{X} / T_{X}$ values as a function of regenerated dose expressed in seconds of exposure to a laboratory beta radiation source. The beta source delivered $\sim 0.079$ to $0.071 \mathrm{~Gy} / \mathrm{s}$ to these coarse-grains mounted on aluminum discs (Grays change because of the length of time between sample analyses, in some cases several years). A dose-response curve is fitted through the points and the intercept of the $L_{N} / T_{N}$ value is used to obtain a $D_{e}$ value (in seconds, and hence then in Gy) for the aliquot. This decay and growth curve show the problems with assuming that just because the decay curve seems to show a fast component does not mean it can be fit with an exponential fit. This curve is a cubic fit. Another explanation for this fit is that the sample is under- irradiated for this aliquot and thus the exponential fit cannot compensate for the high natural signal. 


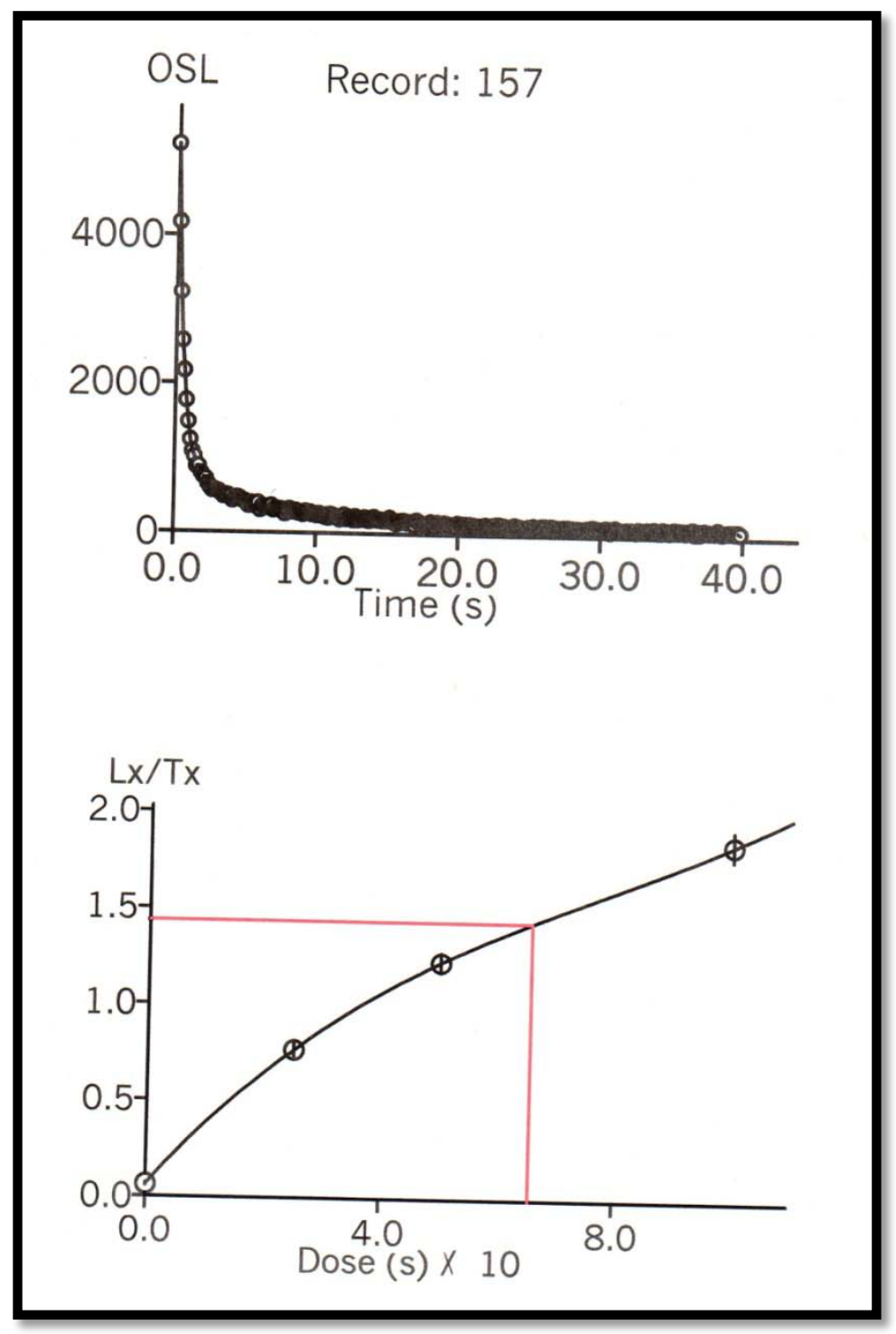

Figure S11. Plot of $\mathrm{L}_{X} / \mathrm{T}_{\mathrm{X}}$ values as a function of regenerated dose expressed in seconds of exposure to a laboratory beta radiation source. The beta source delivered $\sim 0.079$ to $0.071 \mathrm{~Gy} / \mathrm{s}$ to these coarse-grains mounted on aluminum discs (Grays change because of the length of time between sample analyses, in some cases several years). A dose-response curve is fitted through the points and the intercept of the $\mathrm{L}_{N} / \mathrm{T}_{\mathrm{N}}$ value is used to obtain a $\mathrm{D}_{\mathrm{e}}$ value (in seconds, and hence then in Gy) for the aliquot. This decay and growth curve show a "moderate case" scenario for Cypriot samples with a slightly misshapen decay curve but no obvious recuperation at the "zero" point and a decent exponential fit. 


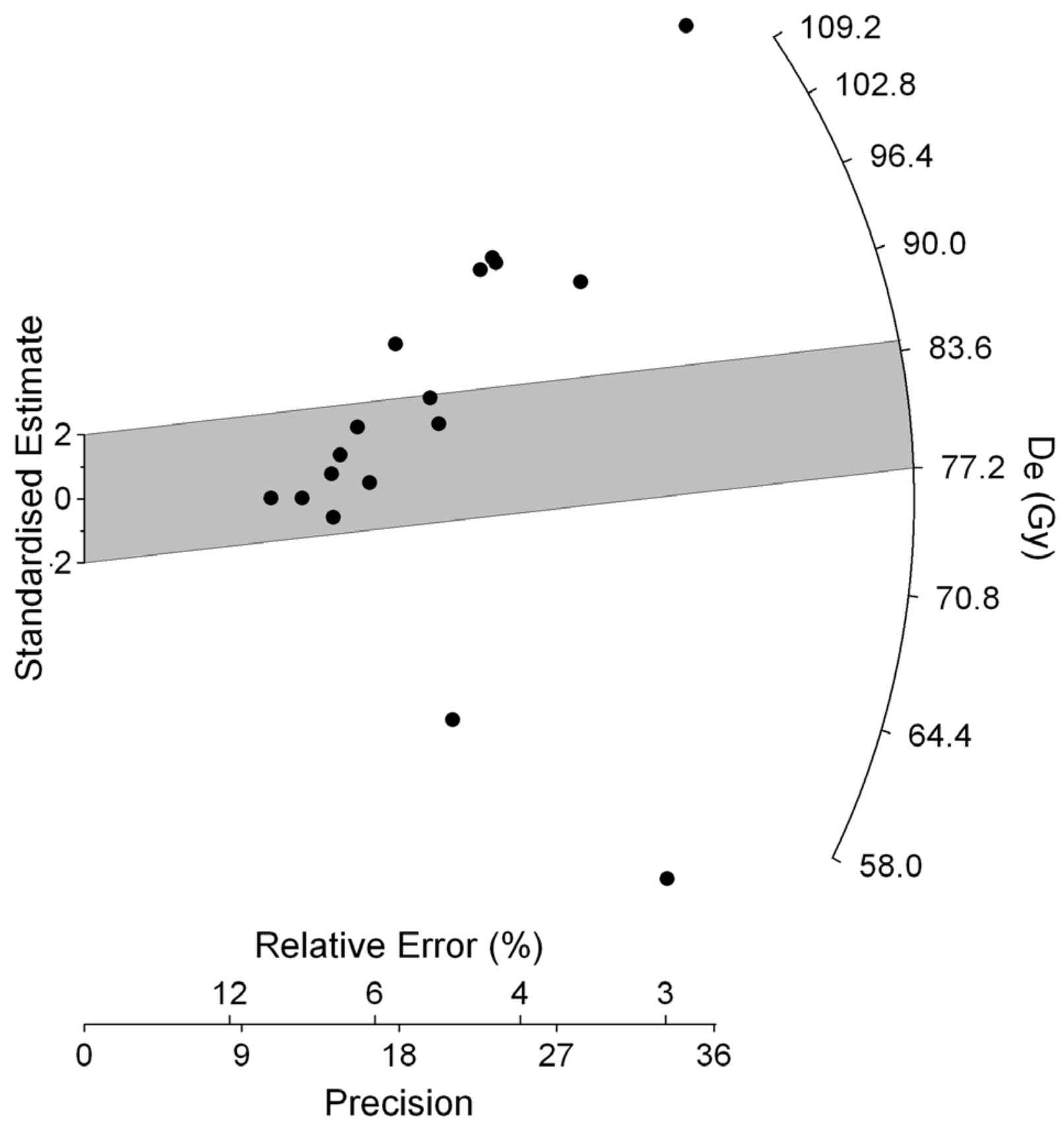

Figure S12. Radial plots allow plotting of each data point with its associated precision; any radius passing through the origin represents a line of constant dose, and the precision of the measurement increases from left to right. This graphical presentation allows visualization of dose distributions, where focus is drawn to the best-known results (Wallinga, 2002). Results are shown for sample $\mathbf{3 / \mathbf { 1 }} \mathbf{1 0} \mathbf{\mathbf { 3 }} \mathbf{\text { (n }}=$ 16). Axis to the left is the standardized estimate within two sigma, axis to the right is the equivalent dose measured (in Gy). There is scatter in the data that might indicate turbated sediment at depth since the equivalent doses are at a lower (and more precise) number as well as partial bleaching (the higher equivalent doses). The average represented here is not the same as the equivalent dose used in the table since that was calculated using a weighted mean. 

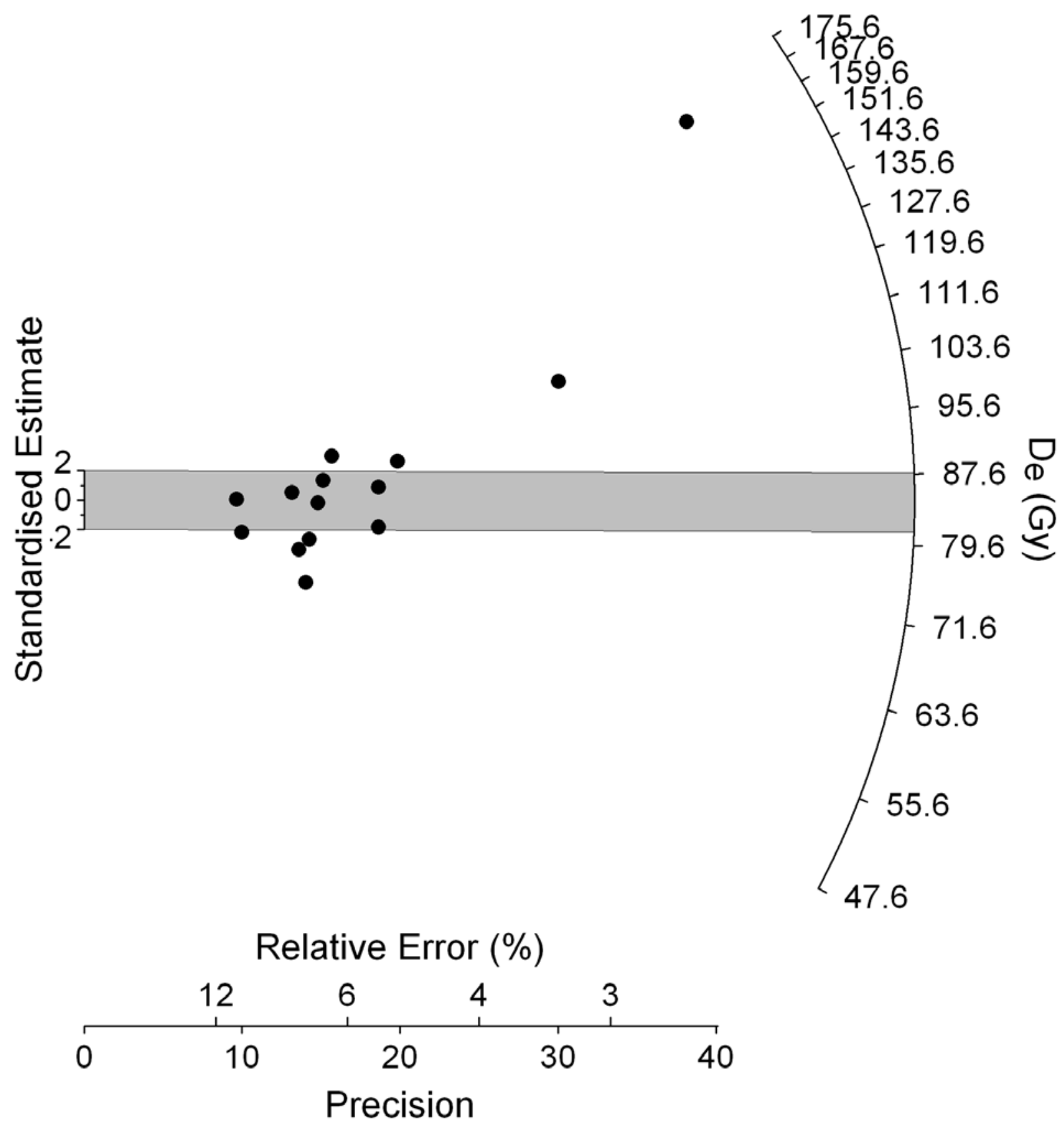

Figure S13. This radial plot shows dose distributions, where focus is drawn to the best-known results (Wallinga, 2002). Results are shown for sample 3/1/10-4 $(\mathbf{n}=\mathbf{1 4})$. Axis to the left is the standardized estimate within two sigma, axis to the right is the equivalent dose measured (in Gy). There is scatter in the data that might indicate partial bleaching sediment since the equivalent doses are at a higher (and more precise) number. 

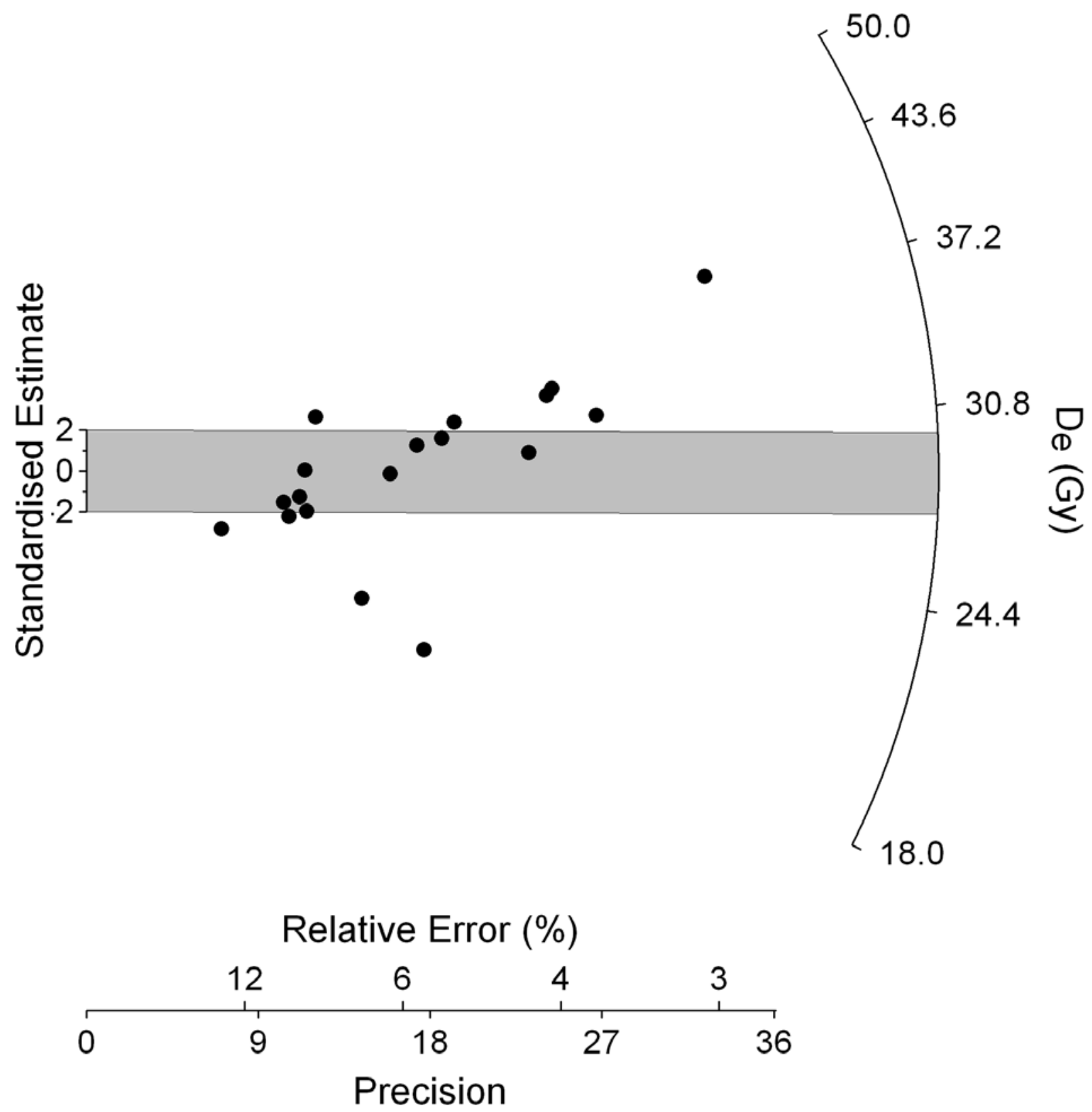

Figure S14. This radial plot shows visualization of dose distributions, where focus is drawn to the bestknown results (Wallinga, 2002). Results are shown for sample 11/21/09-9 $(n=18)$. Axis to the left is the standardized estimate within two sigma, axis to the right is the equivalent dose measured (in Gy). There is scatter in the data that might indicate partial bleaching or turbated sediment at depth. 